(C) 2021, The Authors. Published by Elsevier Inc. and Fass Inc. on behalf of the American Dairy Science Association ${ }^{\circledR}$. This is an open access article under the CC BY-NC-ND license (http://creativecommons.org/licenses/by-nc-nd/4.0/).

\title{
Milk metabolome reveals variations on enteric methane emissions from dairy cows fed a specific inhibitor of the methanogenesis pathway
}

\author{
Bénédict Yanibada, ${ }^{1 *}$ ๑ Ulli Hohenester, ${ }^{1}$ Mélanie Pétéra, ${ }^{2}$ @ Cécile Canlet, ${ }^{3,4}$ Stéphanie Durand, ${ }^{2}$

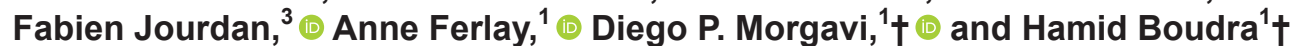 \\ ${ }^{1}$ INRAE, Université Clermont Auvergne, Vetagro Sup, UMRH, 63122, Saint-Genès-Champanelle, France \\ ${ }^{2}$ Université Clermont Auvergne, INRAE, UNH, Plateforme d'Exploration du Métabolisme, MetaboHUB Clermont, F-63000 Clermont-Ferrand, \\ France \\ ${ }^{3}$ Toxalim, Research Centre in Food Toxicology, Université de Toulouse, INRAE, ENVT, INP-Purpan, UPS, F-31027, Toulouse, France \\ ${ }^{4}$ Axiom Platform, MetaToul-MetaboHUB, National Infrastructure for Metabolomics and Fluxomics, F-31027, Toulouse, France
}

\begin{abstract}
Metabolome profiling in biological fluids is an interesting approach for exploring markers of methane emissions in ruminants. In this study, a multiplatform metabolomics approach was used for investigating changes in milk metabolic profiles related to methanogenesis in dairy cows. For this purpose, 25 primiparous Holstein cows at similar lactation stage were fed the same diet supplemented with (treated, $\mathrm{n}=12$ ) or without (control, $\mathrm{n}=13)$ a specific antimethanogenic additive that reduced enteric methane production by $23 \%$ with no changes in intake, milk production, and health status. The study lasted $6 \mathrm{wk}$, with sampling and measures performed in wk 5 and 6 . Milk samples were analyzed using 4 complementary analytical methods, including 2 untargeted (nuclear magnetic resonance and liquid chromatography coupled to a quadrupole-time-of-flight mass spectrometer) and 2 targeted (liquid chromatography-tandem mass spectrometry and gas chromatography coupled to a flame ionization detector) approaches. After filtration, variable selection and normalization data from each analytical platform were then analyzed using multivariate orthogonal partial least square discriminant analysis. All 4 analytical methods were able to differentiate cows from treated and control groups. Overall, 38 discriminant metabolites were identified, which affected 10 metabolic pathways including methane metabolism. Some of these metabolites such as dimethylsulfoxide, dimethylsulfone, and citramalic acid, detected by nuclear magnetic resonance or liquid chromatography-mass spectrometry methods, originated from the rumen microbiota or had a microbial-
\end{abstract}

Received April 1, 2021.

Accepted July 26, 2021.

*Current address: Département des Sciences Animales, Université Laval, Québec, QC, J1V 0A6, Canada.

†Corresponding authors: abdelhamid.boudra@inrae.fr and diego. morgavi@inrae.fr host animal co-metabolism that could be associated with methanogenesis. Also, discriminant milk fatty acids detected by targeted gas chromatography were mostly of ruminal microbial origin. Other metabolites and metabolic pathways significantly affected were associated with AA metabolism. These findings provide new insight on the potential role of milk metabolites as indicators of enteric methane modifications in dairy cows.

Key words: multiplatform metabolomics, methane biomarker, microbial metabolite, milk, dairy cow

\section{INTRODUCTION}

Reduction of enteric methane emissions is an area of interest due to the increased awareness of the necessity of lowering the carbon footprint of ruminant production (Gerber et al., 2013). Methane measurement is performed with techniques such as respiratory chambers, the use of a tracer gas, or automated emissions monitoring such as the GreenFeed system that are not adapted to a large number of animals (Hammond et al., 2016). This is a barrier for the implementation of reliable measurement, reporting, and verification of emissions from the sector and for the assessment and development of mitigation strategies (OECD, 2019). The use of high-throughput indirect methods, although not as precise as direct measurements, can bring benefits for implementing breeding options and testing mitigation approaches on farms (Negussie et al., 2017). The search for alternative indicators of enteric methane emissions has expanded to compounds present in biological matrices, including, in particular, fatty acids (FA) in milk. The rationale of using milk FA is based on the known relation existing between the ruminal production of methane and that of VFA, in particular acetate and butyrate (Morgavi et al., 2010), which are precursors of milk FA in the mammary gland (Ferlay et al., 2017). Also, the presence of odd- and branched- 
chain fatty acids (OBCFA) in milk is due to microbial synthesis and can be associated with rumen functions, including VFA and methane production (Vlaeminck et al., 2006; Fievez et al., 2012). Based on this, numerous studies were performed to identify discriminant FA and link their concentration to enteric methane production (e.g., Chilliard et al., 2009; Dijkstra et al., 2011; Mohammed et al., 2011; Rico et al., 2016; Engelke et al., 2019). The identification and quantification of milk FA is done using GC coupled to a flame ionization detector (GC-FID), although the ability of mid-infrared spectroscopy to predict the quantity of certain milk FA (and other compounds in the mid-infrared spectrum) in a rapid and economic way (De Marchi et al., 2014) has also prompted researchers to test its application as a predictor of methane emissions in dairy cows (e.g., Dehareng et al., 2012; Vanlierde et al., 2015; Shetty et al., 2017; van Gastelen et al., 2018b) .

An extended body of information has been collected worldwide on the relationship between milk FA and methane that consolidates a variety of production conditions and hundreds of individual cow measurements. Notwithstanding, the general consensus is that milk FA have, at best, a moderate predictive power for methane emissions (Mohammed et al., 2011; van Gastelen et al., 2018b; Bougouin et al., 2019a). The prediction power of models can be improved when other parameters are included such as intake and when they are applied to the diets on which they were validated (Mohammed et al., 2011; Rico et al., 2016; Engelke et al., 2019). A probable reason for this lack of universality of prediction models is that milk FA are highly influenced by diet (Newbold and Ramos-Morales, 2020). It is also important that the composition of the diet is known to affect methane emissions (Martin et al., 2010; Knapp et al., 2014).

In contrast, the use of other milk compounds as indicators of enteric methane emissions has received less attention. Metabolomics, using analytical methods based on untargeted or targeted approaches, has the potential to provide the large-scale information on milk metabolites that is required for this purpose. The metabolic profile of milk was already analyzed for this purpose by using nuclear magnetic resonance (NMR) and GC-MS (Antunes-Fernandes et al., 2016), in which several metabolites appeared to be positively or negatively related to methane intensity in cows fed 4 diets differing in the type and proportion of the forage source. In contrast, when using a larger data set based on 6 studies and 27 dietary treatments, there was a weak relation between milk metabolome and methane emissions (van Gastelen et al., 2018a). Similar to the studies on milk FA cited above, reported work on milk metabolites and methane was done using diet as the variation factor influencing emission. Additionally, similar to milk FA, the metabolome of milk is strongly influenced by the diet (Boiani et al., 2019). In contrast, it is not known where the milk metabolome can inform of differences in enteric methane emissions that are not related to diets. Gastrointestinal microbes largely contribute to the pool of metabolites present in the blood of the host animal (Wikoff et al., 2009) and, as a consequence, on other body fluids including milk. We hypothesized that metabolites other than FA originated from, or influenced by, the microbial activity in the rumen can be used to appraise enteric methanogenesis.

The aim of the present study was to explore changes in milk metabolic profiles associated with the reduction of methane emissions. For a wide coverage of the milk metabolome, we used a multiplatform approach that included untargeted and targeted approaches. To circumvent the confounding effect of diet on milk metabolome, we used a single diet that only differed by the presence or not of 3-nitrooxypropanol to induce variation in methane emissions. This antimethanogenic compound was chosen as a model because it specifically inhibits the last step of the methanogenesis pathway and has minimal effect on animal metabolism (Duin et al., 2016; Thiel et al., 2019a).

\section{MATERIALS AND METHODS}

\section{Animals, Experimental Design, Diets, and Procedures}

The study was conducted at the animal facilities of the Herbipole Unit (Herbipole, INRAE; low mountain ruminant experimental facility). Procedures were evaluated and approved by the French Ministry of Education and Research (APAFIS \#2015073116475330) and carried out in accordance with French and European guidelines and regulations for animal experimentation.

The experimental design was previously described (Yanibada et al., 2020). Briefly, 25 Holstein primiparous dairy cows in the same lactation stage $(55 \pm 10$ DIM; mean $\pm \mathrm{SD}$ ) were paired according to calving, DMI and milk yield, and split into 2 balanced groups (control, $\mathrm{n}$ $=13$; treated, $\mathrm{n}=12$ ). At the start of the study, cows had an average DMI of $18 \pm 1.2 \mathrm{~kg}$, an average milk yield of $25 \pm 3.3 \mathrm{~L}$, and an average BW of $608 \pm 36 \mathrm{~kg}$. Cows were housed in a tiestall barn and individually fed ad libitum a TMR diet composed of a DM basis of $35 \%$ corn silage, $30 \%$ grass hay, and $35 \%$ concentrate and premix (Table 1). The diet of the treated group was supplemented with an antimethanogenic additive (60 $\mathrm{mg}$ of 3-nitrooxypropanol $/ \mathrm{kg}$ of $\mathrm{DM})$ that was mixed with the TMR, whereas the control group received a placebo premix. Cows were fed twice daily at 900 and 
$1600 \mathrm{~h}$, and milking was done at 0730 and $1530 \mathrm{~h}$. The study lasted $6 \mathrm{wk}$, with $4 \mathrm{wk}$ of adaptation followed by 2 wk for sampling and measurements.

The effects of the treatment on methane emissions and animal performance were reported elsewhere (Yanibada et al., 2020) and are discussed here in relation to milk metabolites. Briefly, enteric methane emission decreased $\sim 23 \%$ in treated cows, whereas no differences in DMI, milk production, or BW were observed.

\section{Measurements and Sampling Procedures}

Cows were milked twice per day (0730 and $1530 \mathrm{~h}$ ) and daily production was recorded throughout the study. Milk from each cow was analyzed twice per week for fat, protein, and lactose contents using MilkoScan FT (Foss Electric A/S), and SCC was analyzed using FOSS FC (Foss Electric A/S). Individual milk samples $(30 \mathrm{~mL})$ were collected from the morning and afternoon milking, mixed with potassium bichromate (Merck), and stored at $4^{\circ} \mathrm{C}$ until analysis within $24 \mathrm{~h}$ (Lial). For metabolomics analysis, milk samples were collected on 2 consecutive days in wk 5 using the sampling device incorporated in milk meter (DeLaval MM15). Milk collected in the morning and afternoon of the same day were mixed at a 70:30 ratio, reflecting the approximate interval between morning and afternoon milking. Then, samples from d 1 and 2 were pooled in equal parts, aliquoted in fractions of $500 \mu \mathrm{L}$, and stored at $-80^{\circ} \mathrm{C}$ until analysis (Figure 1).

\section{Milk Metabolite Profile Analysis}

Milk samples were analyzed using 4 complementary analytical platforms: 2 untargeted and 2 targeted methods. Untargeted NMR analyses were performed as described (Yanibada et al., 2018). For untargeted ultraperformance liquid chromatography-quadrupole-time of
Table 1. Ingredients and chemical composition of experimental diets

\begin{tabular}{lcc}
\hline Item & Control & Treated \\
\hline Ingredient, \% of DM & & \\
Corn silage & 35 & 35 \\
Grassland hay & 30 & 30 \\
Soybean meal $^{1}$ & 12 & 12 \\
Concentrate $^{2}$ & 21 & 21 \\
Premix $^{2}$ & 2 & 2 \\
Chemical composition, \% of DM & & \\
OM & 94.3 & 94.3 \\
CP & 15.0 & 15.0 \\
NDF & 43.5 & 43.5 \\
ADF & 21.5 & 21.5 \\
Starch & 17.8 & 17.8 \\
Ether extract & 2.8 & 2.8 \\
\hline
\end{tabular}

${ }^{1}$ Concentrate (g/kg of DM): cracked corn (134), barley (65), wheat gluten (120), wheat middlings (250), wheat bran (200) soybean meal (138), dehydrated alfalfa (300), molassed cane (20), carbonate flour (38.6), salt (4), flavoring (4).

${ }^{2}$ The premix contained beet syrup (6\%), sunflower oil (16\%), maize flour $(75 \%)$, and $(3 \%) \mathrm{SiO}_{2}$ in the control group or $(3 \%) \mathrm{SiO}_{2}$ containing $10 \% 3$-nitrooxypropanol in the treated group.

flight (UPLC-QToF)/MS analysis, a sample extraction method was optimized following data quality assessments at each step of the preparation including sonication, protein precipitation, skimming, evaporation, and dissolution in injection solvents. Briefly, in the developed method, milk samples $(500 \mu \mathrm{L})$ were thawed on ice, sonicated for $10 \mathrm{~min}$, and centrifuged at 3,000 $\times \mathrm{g}$ for $15 \mathrm{~min}$ at $4{ }^{\circ} \mathrm{C}$. The top layer was removed and 100 $\mu \mathrm{L}$ of milk were transferred to a $1.5-\mathrm{mL}$ polypropylene tube containing $200 \mu \mathrm{L}$ of cold methanol. The mixture was vortexed and kept at $-20^{\circ} \mathrm{C}$ for $30 \mathrm{~min}$. Then, tubes were centrifuged at $14,000 \times g$ for $10 \mathrm{~min}$ at $4^{\circ} \mathrm{C}$. Supernatants were transferred into glass vials and evaporated to dryness using a Genevac EZ-2 evaporator (Genevac SP Scientific) for 25 min. Dried extracts were resolubilized in a $500-\mu \mathrm{L}$ mixture of MilliQ water/ acetonitrile $(50 / 50, \mathrm{vol} / \mathrm{vol})$ in $0.1 \%$ of formic acid, and $10 \mu \mathrm{L}$ were injected into the liquid chromatography

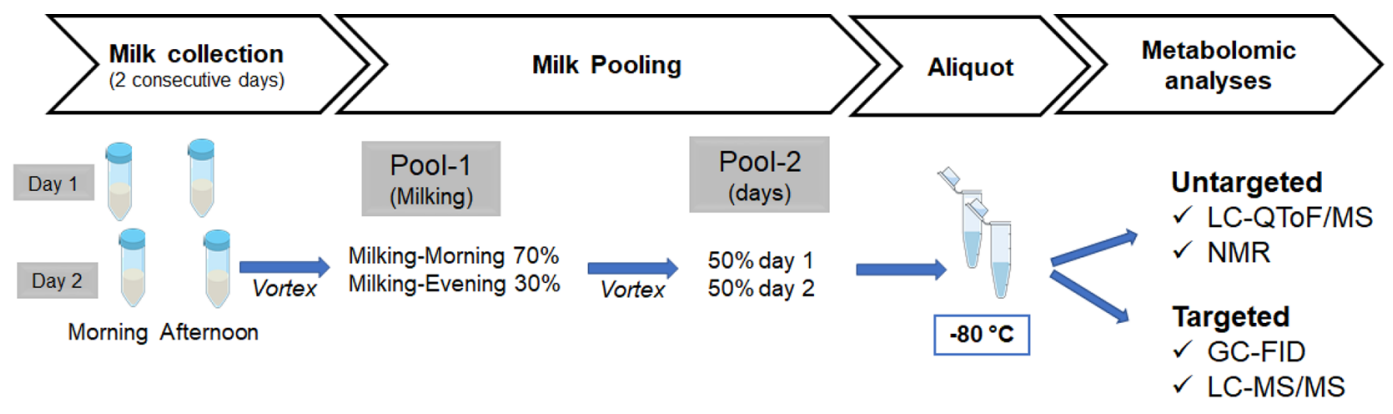

Figure 1. Workflow for preparing milk samples for metabolomics analyses. LC-QToF/MS = liquid chromatography coupled to quadrupole time-of-flight MS; NMR = nuclear magnetic resonance; GC-FID = GC coupled to flame ionization detector; LC-MS/MS = liquid chromatography with tandem MS. 
(LC) system. Analytical conditions were as previously described (Pujos-Guillot et al., 2017). The injection sequence of samples was double randomized using a William's Latin square design with treatment and cows' parameters (weight, DMI, and milk yield) as factors. Each series run had a maximum of 25 samples to ensure the stability of the analytical conditions. In each LCMS run, blank solvent samples $(\mathrm{n}=3)$ were analyzed at the start, followed by sequences consisting of 2 quality control (QC) samples and 5 milk samples. Each run had 10 QC samples. For NMR runs, sequences were of 8 milk samples and $2 \mathrm{QC}(\mathrm{n}=6)$. The $\mathrm{QC}$ were prepared by mixing equal parts of all milk samples. For targeted methods, milk samples were analyzed by LCMS/MS using the Absolute IDQ p180 kit (Biocrates Life Sciences AG). The kit measures 188 metabolites belonging to 7 different biochemical families (AA, biogenic amines, acylcarnitines, lysophosphatidylcholines, phosphatidylcholines, sphingolipids, and monosaccharides; see Supplemental Table S1, https://doi.org/10 .15454/UUZIGD; Yanibada et al., 2021) and GC-FID that characterize specific FA as previously described (Bougouin et al., 2019b).

\section{Data Processing and Statistical Analysis}

The NMR spectra were manually phased and the baseline was corrected using TopSpin 3.2 software (Bruker, GMBH). All spectra were referenced to sodium trimethylsilyl propionate signals at $0 \mathrm{ppm}$, and data were imported in the Amix Software (version 3.9, Bruker) for data reduction. The bucketing was performed in the region [10.0-0.5] ppm with a bucket width of $0.01 \mathrm{ppm}$. Regions in the [5.1-4.5] ppm corresponding to water signal were excluded, as well as those in [5.27-5.21], [5.095-4.41], [4.015-3.53], [3.33-3.27] ppm, corresponding to lactose signals, and [3.39-3.36] ppm, corresponding to methanol signals. A table was generated containing buckets, their chemical shifts, and intensities ( $\mathrm{n}=814$, Supplemental Table S2, https://doi .org/10.15454/UUZIGD; Yanibada et al., 2021). Before multivariate analyses, buckets were normalized to the total intensity of the spectra to avoid any concentration problems.

Mass spectrometry data were processed using Bruker Data Analysis software (Bruker Daltonik) and converted into NetCDF. Features were extracted using a Galaxy open web-based platform (Guitton et al., 2017). Ions were extracted using the centWave algorithm (peak picking) provided by the XCMS tool (Smith et al., 2006). Noisy signals contained in blank solvent samples as well as those outside retention times of $<0.4$ min and $>22$ min were removed. Signal drift and batch effect were corrected using linear modeling based on the QC samples (van der Kloet et al., 2009). As for NMR data, a matrix containing masses, retention times, and intensities was generated $(\mathrm{n}=991$, Supplemental Table S3, https://doi.org/10.15454/UUZIGD; Yanibada et al., 2021). For targeted methods, the Absolute IDQ p180 kit based on LC-MS/MS was able to identify 188 metabolites, of which we selected 126 that had concentrations above the limit of quantification (Supplemental Table S1), whereas 75 FA were detected by GC-FID (Supplemental Table S4, https://doi.org/ 10.15454/UUZIGD; Yanibada et al., 2021).

Data from untargeted and targeted methods were analyzed using SIMCA-P+ software (V13, Umetrics AB). Unsupervised principal component analysis was first used for identifying trends and outliers (Supplemental Figure S1, https://doi.org/10.15454/UUZIGD; Yanibada et al., 2021). A tight cluster of QC samples in the principal component analysis score plots was obtained in both untargeted methods, indicating stable analytical conditions over the time of measurements (Supplemental Figure S1A and S1B). Supervised orthogonal partial least square (OPLS)-discriminant analysis (DA) was performed to highlight variables that discriminate the 2 groups (control vs. treated). All OPLS models were tested for overfitting with a 200-time permutation test. When needed, variable selection was applied for reducing noise issued from not related information (Andersen and Bro, 2010; Galindo-Prieto et al., 2014). For the NMR, an orthogonal signal correction filtering was used to remove the main systematic variability in the data set that was not related to the variability between groups, then a partial least square DA was performed on the obtained data set. For the LC-QToF/MS data, the OPLS-DA model was built using 673 variables out of the 991 original ones, selected by removing those with a variable important in the projection (VIP) value lower than 0.5 on the predictive component of a first overall OPLS-DA model. Discriminant metabolites with VIP values superior to 1.2 for both NMR and MS untargeted methods were selected for further identification. Further, discriminant metabolites were analyzed using univariate analysis ( $t$-test, $P$-value threshold set to 0.05 , XlStat-Biomed, Addinsoft) to identify the most significant ones.

\section{Metabolite Identification for Untargeted Methods}

For NMR, annotation of chemical structures was performed using 2 orthogonal acquisition sequences; that is, 1-dimensional and 2-dimensional NMR J-resolved spectroscopy (Jres), correlated spectroscopy (COSY) and heteronuclear single quantum coherence (HSQC) 
on a pooled sample and compared against pure standards (level 1 of annotation). Chemical shifts in the regions 0.97 to $0.84 \mathrm{ppm}$ and 1.31 to $1.26 \mathrm{ppm}$ suggest that lipids were part of the discriminant compounds, but they could not be identified because this platform is not suitable to accurately characterize lipids. Also, the predominance of lactose signals make the validation of metabolites presents in this area of the NMR 2-dimensional spectra difficult. Indeed, homonuclear (COSY) and heteronuclear (HSQC) lactose correlation signal (Supplemental Figure S2, https://doi.org/ 10.15454/UUZIGD; Yanibada et al., 2021) hampers the visualization of metabolites resonating in this area, affecting their identification. Level 2 of annotation was obtained for metabolites unidentified at level 1 by comparing chemical shifts and coupling constants of signals against those of pure standards that were obtained under the same NMR conditions (internal database), the literature (Klein et al., 2010; Sundekilde et al., 2013; Yang et al., 2016; Li et al., 2017), and public databases such as the Livestock Metabolome Database (Goldansaz et al., 2017; http://lmdb.ca/) or the Biological Magnetic Resonance Data Bank (Ulrich et al., 2008; https://bmrb.io/metabolomics/).

For untargeted LC-QToF/MS data, discriminant metabolites were annotated in a first instance by comparing masses and retention times with data provided by an in-house database containing more than 1,000 metabolites acquired under the same chromatographic conditions. The identity of these metabolites was confirmed by comparing their fragmentation spectra with those of standards acquired under the same conditions (level 1). For the remaining unidentified metabolites, putative annotation of level 2 was achieved by comparing their exact masses or their fragmentation spectra with those provided in public databases (Human Metabolome Database, www.hmdb.ca; Bovine Metabolome Database, https://bovinedb.ca/; Milk Metabolome Database https://mcdb.ca/) and the Kyoto Encyclopedia of Genes and Genomes (KEGG; http://www.genome .jp/ $/ \mathrm{kegg} /)$.

\section{Pathway Analyses}

Network and pathway analyses were performed using discriminant metabolites identified by the 4 analytical platforms that had KEGG identifiers (24 out of 38, Supplemental Table S5, https://doi.org/10.15454/ UUZIGD; Yanibada et al., 2021). These metabolites were implemented in Metaboanalyst 4.0 (Chong et al., 2018; http://www.metaboanalyst.ca) for metabolic pathways analysis.

Discriminant metabolites and pathways were also analyzed using Metexplore (https://metexplore.toulouse .inra.fr/metexplore2/; Cottret et al., 2018). Metabolites with KEGG identification numbers were mapped on Bos taurus KEGG metabolic network (MetExplore Biosource ID 2952). This network is built by assembling all reactions in KEGG for which at least 1 gene coding for an enzyme is found in the annotated Bos taurus genome. Metexplore extracts the reactions connecting the metabolites of interest from the entire metabolic network and produces a reduced metabolic network containing core discriminant reactions (Supplemental Tables S6 and S7, https://doi.org/10.15454/UUZIGD; Yanibada et al., 2021). It uses an algorithm looking for the lightest path between each pair of nodes (weight of the path is the sum of the degree to the square of each metabolite along the path; Chazalviel et al., 2018; Frainay and Jourdan, 2017).

\section{RESULTS AND DISCUSSION}

The study was designed to assess the hypothesis that milk metabolites can reveal ruminal metabolic processes associated with methane production. We adjusted the experimental conditions in a way that minimized the effect of confounding factors known to affect the metabolome. As such, age, parity, lactation stage, and diet were equivalent between the control and treated groups. To modify enteric methane emissions, we used the inhibitor 3-nitrooxypropanol that blocks methyl-coenzyme M reductase (Duin et al., 2016), an enzyme that is found only in methanogenic archaea (Thauer, 2019) and is associated with methane production in the rumen. 3-Nitrooxypropanol, as well as other inhibitors specifically blocking this enzyme, do not have a direct effect on other microbes or on host cells (Zhou et al., 2011; Duin et al., 2016; Webster et al., 2016). In addition, the metabolism and innocuity of 3-nitrooxypropanol has been documented (Thiel et al., 2019a,b), making it a good model compound for detecting metabolic changes when methane production is reduced. As expected, there were no major differences between groups in DMI, milk production, and milk gross composition. In contrast, we observed a reduction of $\sim 23 \%$ in enteric methane emissions ( $\mathrm{g}$ of $\mathrm{CH}_{4} / \mathrm{d}$ ) in the treated group (reported in Yanibada et al., 2020).

\section{Milk FA Profile}

Seventy-five FA were quantified in milk. No significant differences $(P>0.05)$ were observed on sums of saturated, monounsaturated, and polyunsaturated FA, as well as on other distinctive groups such as CLA, but a few individual FA were altered between the 2 groups of cows (Supplemental Table S8, https://doi .org/10.15454/UUZIGD; Yanibada et al., 2021). We 
applied variable selection to reduce noise and used 38 FA to build the OPLS-DA model. The model showed a separation between the 2 groups with a moderate predictive power $\left(\mathrm{Q}^{2}=0.40\right.$; Figure $\left.2 \mathrm{C}\right)$. Seven FA had a VIP threshold higher than 1.2. All these FA decreased in the treated group (Table 2). Notably, OBCFA iso $\mathrm{C} 14$, iso $\mathrm{C} 15$, iso $\mathrm{C} 16$, and $\mathrm{C} 23: 0$, known to be produced by microbial activity in the rumen (Vlaeminck et al., 2006), decreased by $29 \%, 7 \%, 26 \%$, and $14 \%$, respectively. These OBCFA, particularly the iso forms, had already been linked to methane reduction and have been used for predicting methane emissions based on milk FA models (Dijkstra et al., 2011; Bougouin et al., 2019a). Odd and branched-chain FA are synthetized by ruminal bacteria and incorporated into their cell membranes, with their variations in milk associated with modifications in bacterial biomass and abundance of bacterial groups (Fievez et al., 2012). Ruminal bacteria produce iso FA from branched-chain AA Leu and Val and their fermentation products (Massart-Leën and Massart, 1981; Vlaeminck et al., 2006). A reduction of the relative concentration of these essential AA was detected in plasma (Yanibada et al., 2020) and milk of treated cows (see below), and it may be the reason for the lower proportion of OBCFA. Additional measures on the ruminal metabolome and microbiome of
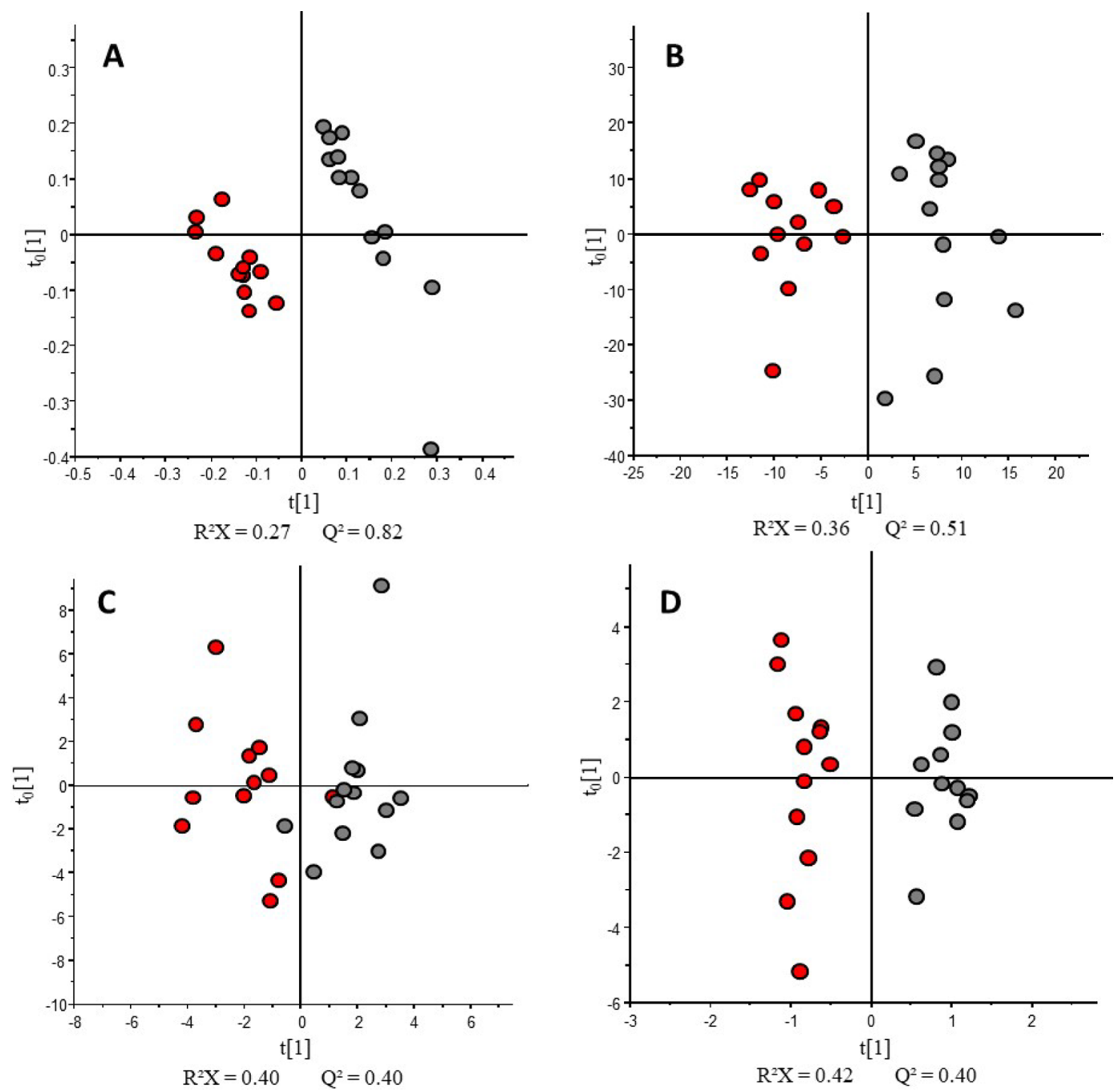

Figure 2. Score plots of orthogonal projection to latent structures-discriminant analysis of untargeted (A) nuclear magnetic resonance ( $\mathrm{R}^{2} \mathrm{X}$ $\left.=0.27 ; \mathrm{Q}^{2}=0.82\right)$, (B) liquid chromatography coupled to a quadrupole-time-of-flight mass spectrometry $\left(\mathrm{R}^{2} \mathrm{X}=0.36 ; \mathrm{Q}^{2}=0.51\right)$ and targeted (C) gas chromatography coupled to a flame ionization detector $\left(\mathrm{R}^{2} \mathrm{X}=0.40 ; \mathrm{Q}^{2}=0.40\right)$ and $(\mathrm{D})$ liquid chromatography-tandem mass spectrometry $\left(\mathrm{R}^{2} \mathrm{X}=0.42 ; \mathrm{Q}^{2}=0.40\right)$ methods. $\mathrm{R}^{2} \mathrm{X}$ represents the explained variance in both predictive $(\mathrm{t}[1])$ and orthogonal (t0[1]) components, and $\mathrm{Q}^{2}$ represents the predictive capacity of the model. Control cows: gray circles $(\mathrm{n}=13, \mathrm{~A}$ and $\mathrm{B} ; \mathrm{n}=12, \mathrm{C}$ and $\mathrm{D})$ and treated cows: red circles $(\mathrm{n}=12)$. 
Table 2. Discriminant milk metabolites in lactating dairy cows with reduced (treated, $\mathrm{n}=12$ ) or unchanged (control, $\mathrm{n}=13$ ) enteric methane emissions identified by 4 complementary analytical methods ${ }^{1,2}$

\begin{tabular}{|c|c|c|c|c|}
\hline Metabolites & $\begin{array}{c}\text { Annotation } \\
\text { level }\end{array}$ & $\mathrm{VIP}^{3}$ & $\begin{array}{c}\text { Fold } \\
\text { change }^{4}\end{array}$ & $P$-value \\
\hline \multicolumn{5}{|l|}{ Untargeted NMR } \\
\hline Leucine $^{5}$ & 1 & 1.83 & 0.74 & $<0.001$ \\
\hline Isoleucine $^{5}$ & 1 & 2.71 & 0.70 & 0.002 \\
\hline Valine $^{5}$ & 2 & 1.45 & 0.77 & 0.002 \\
\hline Glutamic $\operatorname{acid}^{5}$ & 1 & 2.17 & 0.77 & 0.002 \\
\hline Creatine/phosphate & 2 & 5.26 & 1.15 & 0.002 \\
\hline Glutathione & 2 & 1.49 & 0.78 & $<0.001$ \\
\hline Beta-hydroxybutyric acid & 1 & 2.45 & 0.83 & 0.016 \\
\hline Citramalic acid & 2 & 2.71 & 1.99 & $<0.001$ \\
\hline Citric acid & 1 & 9.08 & 1.41 & 0.016 \\
\hline$N$-Acetylglucosamine & 2 & 5.24 & 0.90 & 0.094 \\
\hline Dimethylsulfone & 1 & 5.92 & 1.70 & 0.003 \\
\hline Phosphocholine & 2 & 4.74 & 1.13 & 0.141 \\
\hline \multicolumn{5}{|l|}{ Untargeted LC-QToF/MS } \\
\hline Pyrrolidine & 1 & 1.50 & 0.70 & 0.001 \\
\hline Dimethylsulfoxide & 2 & 1.77 & 6.27 & $<0.001$ \\
\hline Leucine/isoleucine $^{5}$ & 1 & 1.41 & 0.76 & 0.014 \\
\hline Acetyl-L-carnitine & 1 & 1.21 & 0.88 & 0.020 \\
\hline Phenylalanine & 1 & 1.31 & 0.81 & 0.016 \\
\hline \multicolumn{5}{|l|}{ Targeted LC-MS/MS } \\
\hline Glutamic acid ${ }^{5}$ & $\mathrm{NA}^{5}$ & 1.29 & 0.84 & 0.086 \\
\hline Isoleucine $^{5}$ & NA & 2.14 & 0.65 & 0.001 \\
\hline Leucine $^{5}$ & NA & 2.15 & 0.66 & 0.007 \\
\hline Lysine & NA & 2.17 & 0.61 & 0.012 \\
\hline Serine & NA & 1.95 & 1.33 & 0.014 \\
\hline Tyrosine & NA & 1.39 & 0.72 & 0.090 \\
\hline Valine $^{5}$ & NA & 2.62 & 0.61 & $<0.001$ \\
\hline$\alpha$-Amino adipic acid & NA & 1.66 & 0.75 & 0.028 \\
\hline Putrescine & NA & 1.34 & 0.72 & 0.133 \\
\hline Spermidine & NA & 1.80 & 1.29 & 0.023 \\
\hline Spermine & NA & 1.32 & 1.15 & 0.188 \\
\hline Sphingomyelin C22:3 & NA & 1.41 & 1.23 & 0.241 \\
\hline Acylcarnitine (C3) & NA & 1.23 & 0.87 & 0.063 \\
\hline Acylcarnitine (C14:1) & NA & 1.25 & 1.08 & 0.570 \\
\hline Acylcarnitine (C16:2-OH) & NA & 1.21 & 1.07 & 0.523 \\
\hline Lysophosphatidylcholine acyl (C16:0) & NA & 1.22 & 1.07 & 0.706 \\
\hline Phosphatidylcholine diacyl C36:6 & NA & 2.55 & 0.60 & 0.060 \\
\hline Phosphatidylcholine diacyl C36:0 & NA & 1.27 & 1.17 & 0.037 \\
\hline Phosphatidylcholine diacyl C38:0 & NA & 1.29 & 1.18 & 0.048 \\
\hline Phosphatidylcholine acyl-alkyl C30:0 & NA & 1.29 & 1.10 & 0.511 \\
\hline \multicolumn{5}{|l|}{ Targeted GC-FID for milk fatty acids } \\
\hline iso C14:0 & NA & 1.47 & 0.71 & 0.001 \\
\hline iso $\mathrm{C} 15: 0$ & NA & 1.53 & 0.93 & 0.019 \\
\hline iso C16:0 & NA & 1.61 & 0.74 & $<0.001$ \\
\hline C18:2 trans -9, trans-12 & NA & 1.30 & 0.79 & 0.102 \\
\hline $\mathrm{C} 22: 0$ & NA & 1.21 & 0.92 & 0.131 \\
\hline $\mathrm{C} 23: 0$ & NA & 1.36 & 0.86 & 0.004 \\
\hline $\mathrm{C} 22: 2 \mathrm{n}-6$ & NA & 1.20 & 0.84 & 0.061 \\
\hline
\end{tabular}

${ }^{1}$ Methods: untargeted nuclear magnetic resonance (NMR); untargeted liquid chromatography coupled to quadrupole time-of-flight MS (LC-QToF/MS); targeted LC-tandem MS (LC-MS/MS); targeted GC coupled to flame ionization detection (GC-FID),

${ }^{2}$ Cows were fed a TMR with (treated) or without (control) an antimethanogenic compound.

${ }^{3} \mathrm{VIP}=$ variable importance in the projection.

${ }^{4}$ Fold change was calculated by the average value of the treated group to that of the control.

${ }^{5}$ Metabolite identified by other analytical platforms.

${ }^{6} \mathrm{NA}=$ not applicable

these cows would be needed to explain these changes. In addition to the apparent changes in OBCFA, we observed additional differences in a few MUFA (C24:1 cis-15) and PUFA (C22:3n-3; C18:2 trans-9,trans-12, and $\mathrm{C} 22: 2 \mathrm{n}-6)$ that were not identified in other works (reviewed in van Gastelen and Dijkstra, 2016).

With the exception of the OBCFA discussed above, none of the milk FA commonly used in prediction 
equations (review of van Gastelen and Dijkstra, 2016; Bougouin et al., 2019a) were discriminant in this study. This suggested that many of the FA that are reportedly associated with methane emissions reflect differences in diets that are more or less methanogenic. This also explains why prediction equations based exclusively on milk FA perform poorly when tested outside the conditions under which they were created (Bougouin et al., 2019a). Diet is a major driver of milk FA composition and, because we used the same diet in both groups of cows, we did not expect to observe great changes in this study. Milk FA synthesized de novo by the mammary gland (C4:0 to $\mathrm{C} 16: 0)$ and those whose origin can be traced mainly to feeds (C16:0 and longer including unsaturated) (Månsson, 2008) were not discriminant. Contrasting with this result, an increase in short-chain milk FA was reported in cows receiving 3-nitrooxypropanol (van Gastelen et al., 2020; Melgar et al., 2021). The reason of this discrepancy is not obvious; a difference with other works is that in our study all cows were primiparous with a moderate milk yield. Although the predictive power of the OPLS-DA model was only moderate, the results showed that milk FA associated with enteric methane emissions were those directly related to microbial activity in the rumen and none of endogenous or dietary origin FA that are often reported in the literature.

\section{Milk Metabolic Profile Differs Between Control and Treated Cows}

All analytical methods were able to differentiate the 2 groups of animals. The OPLS models showed a clear separation on the first component (Figure 2) with an acceptable predictive ability parameter $\left(\mathrm{Q}^{2}\right)$ of 0.83 for NMR, 0.51 for untargeted LC-QToF/MS, and 0.40 for targeted LC-MS/MS analyses. The combined use of different analytical platforms improved the coverage of milk metabolome with identification of a greater number of discriminant metabolites. Table 2 shows the metabolites $(\mathrm{n}=38)$ driving the separation between groups that were identified in this work (more information on these metabolites is available in Supplemental Tables S9 and S10, https://doi.org/10.15454/UUZIGD; Yanibada et al., 2021). Five of these discriminant metabolites (leucine, isoleucine, valine, glutamic acid and acetyl carnitine) were identified with at least 2 analytical methods.

Among discriminant metabolites found in this work, up to a quarter were free AA and derivatives that generally decreased in the treated group (9 out of 10). Free AA in milk constitute a small fraction of the total pool of AA, and their concentration is affected by diet, stage of lactation, and mastitis (Csapó et al., 1995; Lindmark-Månsson et al., 2003; McDermott et al., 2016). These factors can be discarded in this study as cows were fed the same diet, had similar DMI, and no health issues. Also, digestibility can have an effect on nutrient supply, but it is either positively modified or generally not affected by the feed additive (Jayanegara et al., 2018; van Gastelen et al., 2020). In contrast, the microbial activity in the rumen can influence the amount of free AA in milk (Lindmark-Månsson et al., 2003). Also, of microbial origin, several biogenic amine derivatives of AA were discriminant between control and treated groups. Putrescine decreased, whereas spermidine and spermine increased in treated cows. These biogenic amines are formed from Orn and Arg by decarboxylases, with putrescine being an intermediary of spermidine and spermine synthesis (Benkerroum, 2016). Another discriminant biogenic amine that decreased in treated cows was $\alpha$-aminoadipic acid, a derivative from endogenous Lys degradation. Both lower concentration of $\alpha$-aminoadipic acid and greater concentration of spermidine were correlated with higher milk protein content in Holstein dairy cows (Melzer et al., 2013). This is in agreement with the tendency for greater milk protein content in treated cows (Yanibada et al., 2020).

In addition, we observed higher levels of creatine and its phosphorylated derivative phosphocreatine in the treated group. Creatine in ruminants is mainly of endogenous origin synthetized from Gly and Arg in kidneys and liver with a final step in the liver requiring methionine (Mato and Lu, 2007). These metabolites are implicated in intracellular energy metabolism (Wallimann et al., 2011). We also identified phosphocholine, glycerophosphocholines, and acylcarnitines among discriminant metabolites. These metabolites are normal constituents in cow milk and have important functions in cellular metabolism associated with $\mathrm{FA}$ oxidation and energy balance (Erfle et al., 1970; Pinotti et al., 2002; Sundekilde et al., 2011). For instance, decreased levels of $\beta$-hydroxybutyric acid and acetyl carnitine, and increased levels of glycerophosphocholine in treated cows have been linked also to better energy balance (Erfle et al., 1970; Klein et al., 2012). In contrast, acetyl carnitine in milk was negatively associated with methane emissions by van Gastelen et al. (2017). This contradictory result needs clarification, but it is possible that all these metabolites, mainly produced by mammalian tissues and requiring active transport mechanisms (Shennan and Peaker, 2000), do not specifically signal the methane-emission status but rather a general status of the host animal. This is probably the case for citric acid that is secreted by the epithelial cells of the mammary gland by exocytosis and reflects this 
organ activity (Shennan and Peaker, 2000). Citric acid increased by $41 \%$ in treated cows, similar to previously reported (van Gastelen et al., 2018a).

\section{Pathways Analysis and Relationships Between Metabolites}

Metabolic pathways analysis of discriminant metabolites highlighted 10 affected pathways $(P>0.05$, impact-value threshold $\geq 0.2$ ) including methane metabolism and 9 pathways of AA metabolism (Figure 3). These different pathways may have interactions, with changes in 1 pathway affecting others. To obtain an integrative view, we used MetExplore, a tool that is able to highlight these interactions between pathways. MetExplore, when applied to the Bos taurus KEGG metabolic network, produced a subnetwork linking 19 discriminant metabolites and 6 pathways (Figure 4, subnetwork data are available on Supplemental Table S7, https://doi.org/10.15454/UUZIGD; Yanibada et al., 2021). This subnetwork showed how the affected pathways were related and that they shared common metabolites. Notably, glutamic acid played a central role in several linked pathways, suggesting an important role for this metabolite. This approach can be used for selecting key metabolites in affected pathways to be used for refinement of biomarkers and future validation studies. Five metabolites (with KEGG IDs) could not be mapped on the subnetwork. These were citramalic acid, acetylcarnitine, and docosanoic acid, which were not captured probably because the network needs to be better curated. Nonetheless, citramalic acid is also associated with microbial metabolism (Zheng et al., 2011). The other 2 metabolites were dimethylsulfone and dimethylsulfoxide, which are known to be produced by the microbiota (He and Slupsky, 2014). Interestingly, these microbial metabolites can be linked to methanogenesis (see subheading below).

\section{Milk Metabolites as Potential Proxies of Reduced Enteric Methane Production}

The use of milk metabolites as indirect indicators of methane emissions in dairy cattle has undeniable advantages for application in the field, but the accuracy of the predictions is still not robust enough (Negussie et al., 2017). This is because the mammary gland is distal from the rumen, where most of the enteric methane is produced; additionally, there are intermediate organs such as the liver and the intravascular blood compartment that further modulate the metabolome. Furthermore, the mammary gland is a dynamic organ that synthesizes most major milk components and actively uptakes or blocks metabolites from blood. For this reason, and as a result of the use of the same diet, we essentially expected changes in minor metabolites and of a modest nature. Despite these imposed constraints, we showed that the metabolic profile in milk can discriminate cows that had a moderate reduction in methane emission of $\sim 20 \%$.

In this work, we scanned a large range of metabolites that were detected through targeted and untargeted metabolomic platforms. We also analyzed milk FA that included the milk constituents most commonly used for predicting enteric methane emissions. The purpose was not to provide new regression models, but rather to highlight novel elements for examining the systemic consequences and highlight potential markers of reduced enteric methanogenesis. We found that several discriminant metabolites were associated with pathways of AA and energy metabolism. Although their variation was less marked than in plasma (Yanibada et al., 2020),

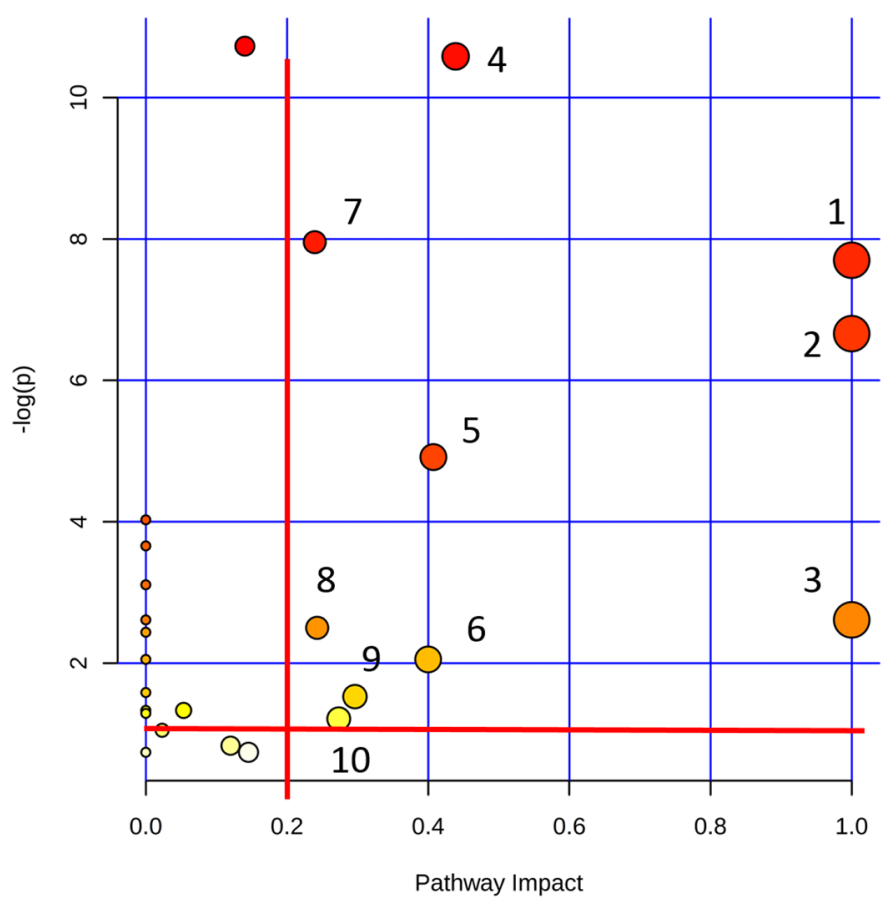

Figure 3. Pathways affected by the reduction of methane emissions. From the 38 discriminant metabolites, 24 could be mapped on the Bos taurus network using Kyoto Encyclopedia of Genes and Genomes (http://www.genome.jp/kegg/) identifiers. Pathways significantly affected were as follows: (1) valine, leucine, and isoleucine biosynthesis; (2) phenylalanine, tyrosine and tryptophan biosynthesis; (3) D-glutamine and D-glutamate metabolism; (4) glutathione metabolism; (5) phenylalanine metabolism; (6) methane metabolism; (7) arginine and proline metabolism; (8) glycine, serine, and threonine metabolism; (9) glyoxylate and dicarboxylate metabolism; and (10) alanine, aspartate, and glutamate metabolism. The plot was built based on the pathway enrichment analysis (node colors) and on the pathway impact values resulting from the pathway topology analysis (node size). The red lines correspond to a threshold of $-\log (P)=1.3$ and a pathway impact $=0.2$. 


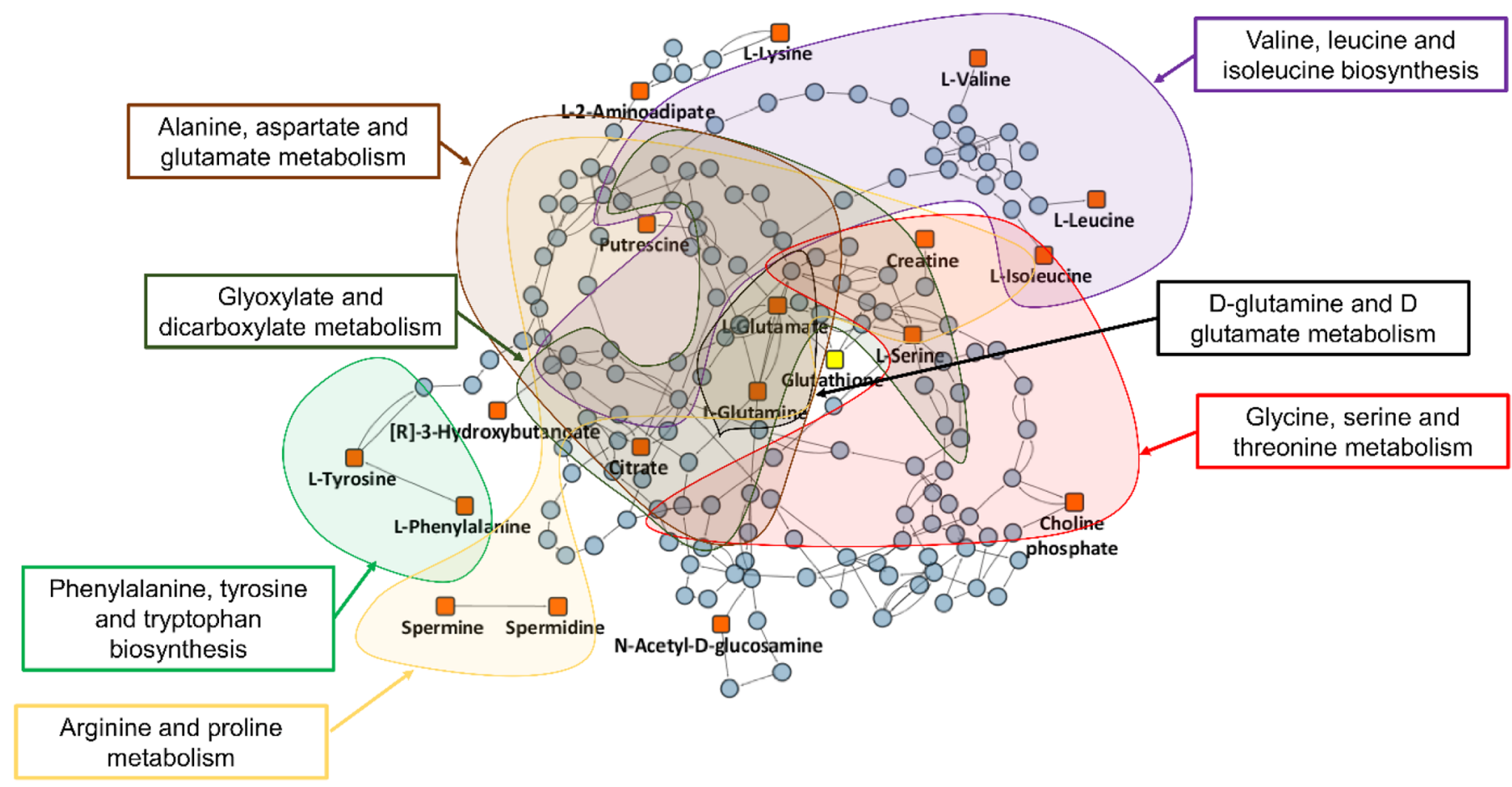

Figure 4. Metabolic subnetwork created by MetExplore using Bos Taurus network, showing the link between metabolites associated with a reduction of enteric methane emissions (19 metabolites with Kyoto Encyclopedia of Genes and Genomes identifiers; http://www.genome.jp/ kegg/). The subnetwork includes 19 discriminant metabolites (orange squares) and 156 intermediary metabolites (blue circles). Pathways highlighted with Metaboanalyst (http://www.metaboanalyst.ca) that include the discriminant metabolites are colored.

the result further suggests a systemic metabolic effect on the host animal when methane is inhibited. More interestingly, some discriminant metabolites can be associated with microbial metabolism, and more specifically to methane. In addition to OBCFA discussed above, in treated cows, we observed an increase of $527 \%$ for dimethylsulfoxide and $70 \%$ for dimethylsulfone as compared with the control. These 2 metabolites had the highest and second highest VIP in their respective multivariate models, indicating their importance. In the gastrointestinal tract, they are both synthetized from methanethiol, a degradation product of Met (He and Slupsky, 2014). Higher amount of proteins as a source of Met has been related to higher levels of these metabolites in milk (Villeneuve et al., 2013). As the amount of protein and nitrogen in the diet was the same, we hypothesize that more microbial protein is synthetized and recycled in the rumen (Wallace et al., 1997). This leads to a higher availability of AA to the host, which is concurrent with the higher plasmatic level of Met detected in the treated group (Yanibada et al., 2020). Dimethylsulfoxide, dimethylsulfone, Met, and some of their intermediate metabolites are all sulfur- and methyl-containing compounds that have been negatively correlated with methane emissions under different conditions (Morgavi et al., 2010; Martinez-Fernandez et al., 2018; Saro et al., 2018). Other discriminant metabolites that can be of bacterial origin were citramalic acid, a methylated analog of malic acid that increased in the treated group, and $\mathrm{N}$-acetylglucosamine, which is suggested to be a byproduct metabolite of Methanobrevibacter gottschalkii (Islam et al., 2019) and decreased when methanogenesis was inhibited in this study.

It is also noted that the most discriminant metabolites cannot be ascribed to the known metabolism of 3-nitrooxypropanol that is degraded mainly into $\mathrm{CO}_{2}$ (Thiel et al., 2019a). Some 3-nitrooxypropanol metabolites can be incorporated into carbohydrates, but the amount of additive ingested was less than $1.2 \mathrm{~g} /$ cow per day, precluding a significant influence on the metabolome. Notwithstanding, these discriminant metabolites should be validated with a higher number of cows for their capability to uncover natural emission variation and under various conditions, including the use of other methane inhibitors.

Nine discriminant metabolites found in milk are also discriminant in plasma (Yanibada et al., 2020). They are AA and derivatives (leucine, isoleucine, valine, serine, tyrosine, and pyrrolidine) that were, as expected, found at higher levels in plasma. However, dimethylsulfone, creatine, and citric acid are higher in milk. We applied Pearson correlation between plasma and milk 


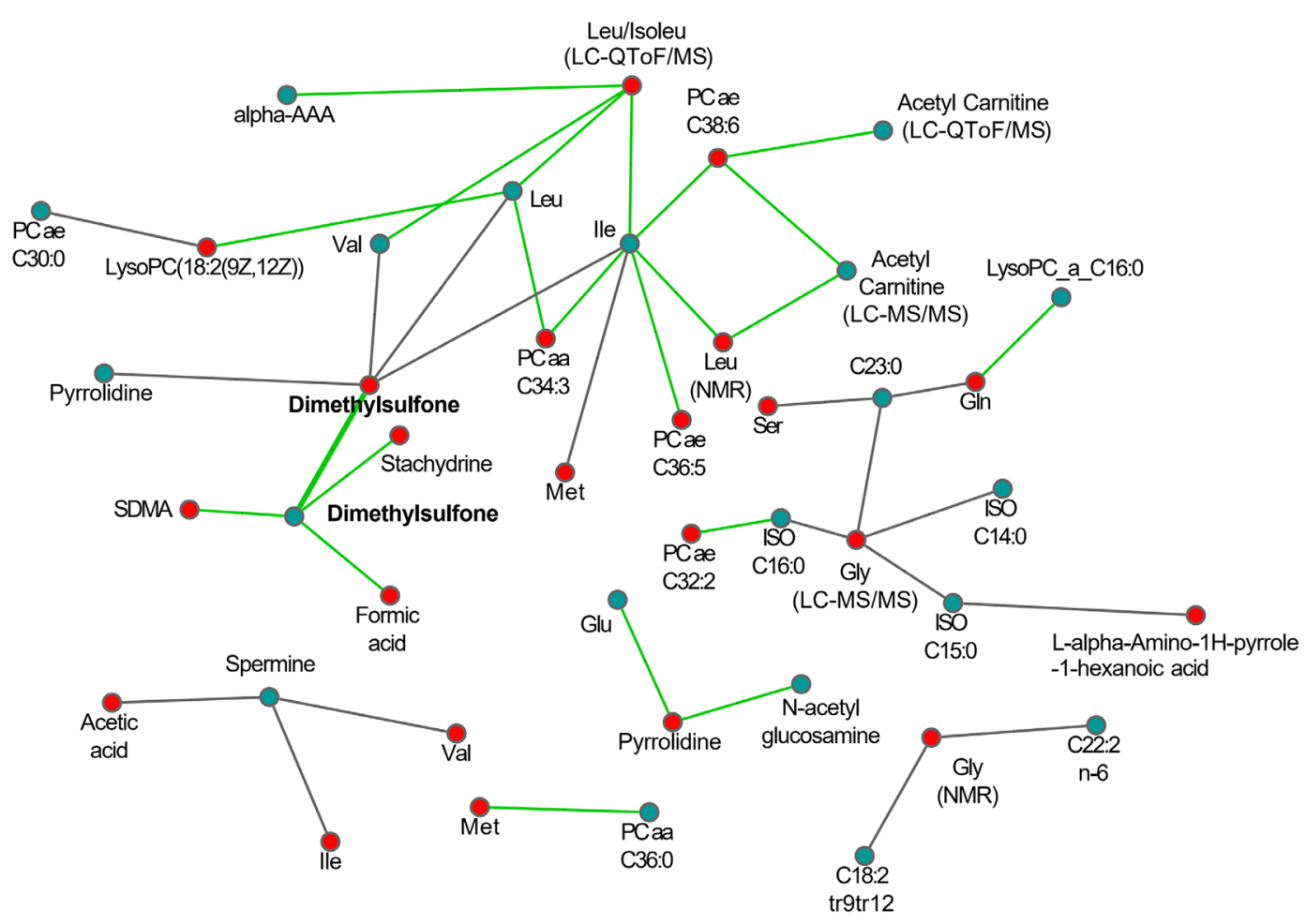

Figure 5. Pearson correlations ( $\mathrm{r}>0.6$ ) between plasma (red) and milk (blue) discriminant metabolites. Gray edges represent negative correlations; green edges represent positive correlations. The strongest correlation was $\mathrm{r}=0.96$ between milk and plasma dimethylsulfone highlighted in bold. Discriminant metabolites from the same biological matrix identified by more than one detection method are indicated as NMR for nuclear magnetic resonance, LC-QToF/MS for liquid chromatography coupled to quadrupole-time-of-flight MS and LC-MS/MS for liquid chromatography-tandem MS (see text for details).

metabolites to explore potential links not highlighted by the pathway analyses described above. Using a threshold of 0.6 for considering a correlation significant, we highlighted 42 correlations out of the 4855 tested for the 2 matrices. To be noted, we observed a cluster with strong positive correlation between milk and plasma dimethylsulfone (0.96). Milk dimethylsulfone also showed a good correlation with plasma formic acid and stachydrine, 2 metabolites associated with rumen microbes and methane (Figure 5 and Supplemental Table S11, https://doi.org/10.15454/UUZIGD; Yanibada et al., 2021).

\section{CONCLUSIONS}

This work showed that the milk metabolome reflected differences in enteric methane emissions from lactating dairy cows. We identified 38 discriminant metabolites, and up to 10 affected metabolic pathways. Many of these metabolites that were found at greater concentrations in low-methane-emitting cows are general indicators of an unimpaired metabolic status. As cows were under similar physiological conditions and were fed the same diet, this finding implies that reduced methane production has a nonnegative effect on the overall nutritional condition. Importantly, some milk metabolites have the features of being of microbial origin and associated with methanogenesis. The results support the hypothesis that distant metabolites in milk reveal enteric methanogenesis variation in dairy cows.

\section{ACKNOWLEDGMENTS}

Bénédict Yanibada was supported by a CIFRE (Industrial Agreements of Training by Research) PhD studentship funded by the ANRT (National Association of Research and Technology, Paris, France). We thank E. Tixier for laboratory analysis and the personnel of the Experimental Unit Herbipôle for the care of animals (UMRH, INRAE). This study is part of a collaborative project led by INRA and funded by 11 institutes and private companies: Adisseo France SAS (Antony, France), Agrial (Caen, France), APIS-GENE (Paris, France), Deltavit (Janzé, France), DSM Nutritional Products AG (Kaiseraugst, Switzerland), Institut de l'Elevage (Paris, France), Lallemand (Blagnac, France), Moy Park Beef Orléans, (Fleury-les-Aubrais, France), Neovia (Saint Nolff, France), Techna France Nutri- 
tion (Couëron, France), and Valorex (Combourtille, France). Untargeted metabolomic analyses by mass spectrometry were performed within the metaboHUB French infrastructure (ANR-INBS-0010). The authors declare that the research was conducted in the absence of any commercial or financial relationships that could be construed as a potential conflict of interest.

\section{REFERENCES}

Andersen, C. M., and R. Bro. 2010. Variable selection in regression-A tutorial. J. Chem. 24:728-737. https://doi.org/10.1002/cem.1360.

Antunes-Fernandes, E. C., S. van Gastelen, J. Dijkstra, K. A. Hettinga, and J. Vervoort. 2016. Milk metabolome relates enteric methane emission to milk synthesis and energy metabolism pathways. J. Dairy Sci. 99:6251-6262. https://doi.org/10.3168/jds.2015-10248.

Benkerroum, N. 2016. Biogenic amines in dairy products: Origin, incidence, and control means. Compr. Rev. Food Sci. Food Saf. 15:801-826. https://doi.org/10.1111/1541-4337.12212.

Boiani, M., U. Sundekilde, L. M. Bateman, D. G. McCarthy, A. R. Maguire, A. Gulati, T. P. Guinee, M. Fenelon, D. Hennessy, R. J. FitzGerald, and P. M. Kelly. 2019. Integration of high and low field H-1 NMR to analyse the effects of bovine dietary regime on milk metabolomics and protein-bound moisture characterisation of the resulting mozzarella cheeses during ripening. Int. Dairy J. 91:155-164. https://doi.org/10.1016/j.idairyj.2018.08.016.

Bougouin, A., J. Appuhamy, A. Ferlay, E. Kebreab, C. Martin, P. J. Moate, C. Benchaar, P. Lund, and M. Eugene. 2019a. Individual milk fatty acids are potential predictors of enteric methane emissions from dairy cows fed a wide range of diets: Approach by meta-analysis. J. Dairy Sci. 102:10616-10631. https://doi.org/10 $.3168 /$ jds.2018-15940.

Bougouin, A., C. Martin, M. Doreau, and A. Ferlay. 2019b. Effects of starch-rich or lipid-supplemented diets that induce milk fat depression on rumen biohydrogenation of fatty acids and methanogenesis in lactating dairy cows. Animal 13:1421-1431. https://doi.org/10 $1017 /$ S1751731118003154.

Chazalviel, M., C. Frainay, N. Poupin, F. Vinson, B. Merlet, Y. Gloaguen, L. Cottret, and F. Jourdan. 2018. MetExploreViz: web component for interactive metabolic network visualization. Bioinformatics 34:312-313. https://doi.org/10.1093/bioinformatics/ btx588.

Chilliard, Y., C. Martin, J. Rouel, and M. Doreau. 2009. Milk fatty acids in dairy cows fed whole crude linseed, extruded linseed, or linseed oil, and their relationship with methane output. J. Dairy Sci. 92:5199-5211. https://doi.org/10.3168/jds.2009-2375.

Chong, J., O. Soufan, C. Li, I. Caraus, S. Li, G. Bourque, D. S. Wishart, and J. Xia. 2018. MetaboAnalyst 4.0: Towards more transparent and integrative metabolomics analysis. Nucleic Acids Res. 46(W1):W486-W494. https://doi.org/10.1093/nar/gky310.

Cottret, L., C. Frainay, M. Chazalviel, F. Cabanettes, Y. Gloaguen, E. Camenen, B. Merlet, S. Heux, J. C. Portais, N. Poupin, F. Vinson, and F. Jourdan. 2018. MetExplore: Collaborative edition and exploration of metabolic networks. Nucleic Acids Res. 46(W1):W495-W502. https://doi.org/10.1093/nar/gky301.

Csapó, J., Z. Csapó-Kiss, J. Stefler, T. G. Martin, and S. Némethy. 1995. Influence of mastitis on D-amino acid content of milk. J. Dairy Sci. 78:2375-2381. https://doi.org/10.3168/jds.S0022 $-0302(95) 76865-5$.

De Marchi, M., V. Toffanin, M. Cassandro, and M. Penasa. 2014 Invited review: Mid-infrared spectroscopy as phenotyping tool for milk traits1. J. Dairy Sci. 97:1171-1186. https://doi.org/10.3168/ jds.2013-6799.

Dehareng, F., C. Delfosse, E. Froidmont, H. Soyeurt, C. Martin, N. Gengler, A. Vanlierde, and P. Dardenne. 2012. Potential use of milk mid-infrared spectra to predict individual methane emission of dairy cows. Animal 6:1694-1701. https://doi.org/10.1017/ S1751731112000456.
Dijkstra, J., S. M. van Zijderveld, J. A. Apajalahti, A. Bannink, W. J. J. Gerrits, J. R. Newbold, H. B. Perdok, and H. Berends. 2011. Relationships between methane production and milk fatty acid profiles in dairy cattle. Anim. Feed Sci. Technol. 166-167:590-595. https://doi.org/10.1016/j.anifeedsci.2011.04.042.

Duin, E. C., T. Wagner, S. Shima, D. Prakash, B. Cronin, D. R. Yanez-Ruiz, S. Duval, R. Rumbeli, R. T. Stemmler, R. K. Thauer, and M. Kindermann. 2016. Mode of action uncovered for the specific reduction of methane emissions from ruminants by the small molecule 3-nitrooxypropanol. Proc. Natl. Acad. Sci. USA 113:6172-6177. https://doi.org/10.1073/pnas.1600298113.

Engelke, S. W., G. Das, M. Derno, A. Tuchscherer, K. Wimmers, M. Rychlik, H. Kienberger, W. Berg, B. Kuhla, and C. C. Metges. 2019. Methane prediction based on individual or groups of milk fatty acids for dairy cows fed rations with or without linseed. J. Dairy Sci. 102:1788-1802. https://doi.org/10.3168/jds.2018-14911.

Erfle, J. D., L. J. Fisher, and F. Sauer. 1970. Carnitine and acetylcarnitine in the milk of normal and ketotic cows. J. Dairy Sci. 53:486-489. https://doi.org/10.3168/jds.S0022-0302(70)86236-1.

Ferlay, A., L. Bernard, A. Meynadier, and C. Malpuech-Brugère. 2017. Production of trans and conjugated fatty acids in dairy ruminants and their putative effects on human health: A review. Biochimie 141:107-120. https://doi.org/10.1016/j.biochi.2017.08.006.

Fievez, V., E. Colman, J. M. Castro-Montoya, I. Stefanov, and B. Vlaeminck. 2012. Milk odd- and branched-chain fatty acids as biomarkers of rumen function-An update. Anim. Feed Sci. Technol. 172:51-65. https://doi.org/10.1016/j.anifeedsci.2011.12.008.

Frainay, C., and F. Jourdan. 2017. Computational methods to identify metabolic sub-networks based on metabolomic profiles. Brief. Bioinform. 18:43-56. https://doi.org/10.1093/bib/bbv115.

Galindo-Prieto, B., L. Eriksson, and J. Trygg. 2014. Variable influence on projection (VIP) for orthogonal projections to latent structures (OPLS). J. Chem. 28:623-632. https://doi.org/10.1002/cem.2627.

Gerber, P. J., H. Steinfeld, B. Henderson, A. Mottet, C. Opio, J. Dijkman, A. Falcucci, and G. Tempio. 2013. Tackling climate change through livestock - A global assessment of emissions and mitigation opportunities. Food and Agriculture Organization of the United Nations (FAO).

Goldansaz, S. A., A. C. Guo, T. Sajed, M. A. Steele, G. S. Plastow, and D. S. Wishart. 2017. Livestock metabolomics and the livestock metabolome: A systematic review. PLoS One 12:e0177675. https:/ /doi.org/10.1371/journal.pone.0177675.

Guitton, Y., M. Tremblay-Franco, G. Le Corguille, J. F. Martin, M. Petera, P. Roger-Mele, A. Delabriere, S. Goulitquer, M. Monsoor, C. Duperier, C. Canlet, R. Servien, P. Tardivel, C. Caron, F. Giacomoni, and E. A. Thevenot. 2017. Create, run, share, publish, and reference your LC-MS, FIA-MS, GC-MS, and NMR data analysis workflows with the Workflow4Metabolomics 3.0 Galaxy online infrastructure for metabolomics. Int. J. Biochem. Cell Biol. 93:89-101. https://doi.org/10.1016/j.biocel.2017.07.002.

Hammond, K., L. A. Crompton, A. Bannink, J. Dijkstra, D. R. YanezRuiz, P. O'Kiely, E. Kebreab, M. A. Eugene, Z. Yu, K. J. Shingfield, A. Schwarm, A. N. Hristov, and C. K. Reynolds. 2016. Review of current in vivo measurement techniques for quantifying enteric methane emission from ruminants. Anim. Feed Sci. Technol. 219:13-30. https://doi.org/10.1016/j.anifeedsci.2016.05.018.

He, X., and C. M. Slupsky. 2014. Metabolic fingerprint of dimethyl sulfone (DMSO2) in microbial-mammalian co-metabolism. J. Proteome Res. 13:5281-5292. https://doi.org/10.1021/pr500629t.

Islam, M. M., S. C. Fernando, and R. Saha. 2019. Metabolic modeling elucidates the transactions in the rumen microbiome and the shifts upon virome interactions. Front. Microbiol. 10:2412. https://doi .org/10.3389/fmicb.2019.02412.

Jayanegara, A., K. A. Sarwono, M. Kondo, H. Matsui, M. Ridla, E. B. Laconi, and Nahrowi.. 2018. Use of 3-nitrooxypropanol as feed additive for mitigating enteric methane emissions from ruminants: A meta-analysis. Ital. J. Anim. Sci. 17:650-656. https://doi.org/10 $.1080 / 1828051 X .2017 .1404945$.

Klein, M. S., M. Almstetter, G. Schlamberger, N. Nürnberger, K. Dettmer, P. Oefner, H. Meyer, S. Wiedemann, and W. Gronwald. 2010. Nuclear magnetic resonance and mass spectrometry-based 
milk metabolomics in dairy cows during early and late lactation. J. Dairy Sci. 93:1539-1550. https://doi.org/10.3168/jds.2009-2563.

Klein, M. S., N. Buttchereit, S. P. Miemczyk, A. K. Immervoll, C. Louis, S. Wiedemann, W. Junge, G. Thaller, P. J. Oefner, and W. Gronwald. 2012. NMR metabolomic analysis of dairy cows reveals milk glycerophosphocholine to phosphocholine ratio as prognostic biomarker for risk of ketosis. J. Proteome Res. 11:1373-1381. https://doi.org/10.1021/pr201017n.

Knapp, J. R., G. L. Laur, P. A. Vadas, W. P. Weiss, and J. M. Tricarico. 2014. Invited review: Enteric methane in dairy cattle production: quantifying the opportunities and impact of reducing emissions. J. Dairy Sci. 97:3231-3261. https://doi.org/10.3168/jds .2013-7234.

Li, Q., Z. Yu, D. Zhu, X. Meng, X. Pang, Y. Liu, R. Frew, H. Chen, and G. Chen. 2017. The application of NMR-based milk metabolite analysis in milk authenticity identification. J. Sci. Food Agric. 97:2875-2882. https://doi.org/10.1002/jsfa.8118.

Lindmark-Månsson, H., R. Fondén, and H. E. Pettersson. 2003. Composition of Swedish dairy milk. Int. Dairy J. 13:409-425. https:// doi.org/10.1016/S0958-6946(03)00032-3.

Månsson, H. L. 2008. Fatty acids in bovine milk fat. Food Nutr. Res. 52:1-3. https://doi.org/http://doi.org/10.3402/fnr.v52i0.1821.

Martin, C., D. P. Morgavi, and M. Doreau. 2010. Methane mitigation in ruminants: From microbe to the farm scale. Animal 4:351-365. https://doi.org/10.1017/S1751731109990620.

Martinez-Fernandez, G., S. Duval, M. Kindermann, H. J. Schirra, S. E. Denman, and C. S. McSweeney. 2018. 3-NOP vs. halogenated compound: Methane production, ruminal fermentation and microbial community response in forage fed cattle. Front. Microbiol. 9:1582. https://doi.org/10.3389/fmicb.2018.01582.

Massart-Leën, A. M., and D. L. Massart. 1981. The use of clustering techniques in the elucidation or confirmation of metabolic pathways. Application to the branched-chain fatty acids present in the milk fat of lactating goats. Biochem. J. 196:611-618. https://doi .org/10.1042/bj1960611.

Mato, J. M., and S. C. Lu. 2007. Role of S-adenosyl-L-methionine in liver health and injury. Hepatology 45:1306-1312. https://doi.org/ 10.1002/hep.21650.

McDermott, A., G. Visentin, M. De Marchi, D. P. Berry, M. A. Fenelon, P. M. O'Connor, O. A. Kenny, and S. McParland. 2016. Prediction of individual milk proteins including free amino acids in bovine milk using mid-infrared spectroscopy and their correlations with milk processing characteristics. J. Dairy Sci. 99:3171-3182. https://doi.org/10.3168/jds.2015-9747.

Melgar, A., C. F. A. Lage, K. Nedelkov, S. E. Raisanen, H. Stefenoni, M. E. Fetter, X. Chen, J. Oh, S. Duval, M. Kindermann, N. D. Walker, and A. N. Hristov. 2021. Enteric methane emission, milk production, and composition of dairy cows fed 3-nitrooxypropanol. J. Dairy Sci. 104:357-366. https://doi.org/10.3168/jds.2020 -18908 .

Melzer, N., D. Wittenburg, S. Hartwig, S. Jakubowski, U. Kesting, L. Willmitzer, J. Lisec, N. Reinsch, and D. Repsilber. 2013. Investigating associations between milk metabolite profiles and milk traits of Holstein cows. J. Dairy Sci. 96:1521-1534. https://doi .org/10.3168/jds.2012-5743.

Mohammed, R., S. M. McGinn, and K. A. Beauchemin. 2011. Prediction of enteric methane output from milk fatty acid concentrations and rumen fermentation parameters in dairy cows fed sunflower, flax, or canola seeds. J. Dairy Sci. 94:6057-6068. https://doi.org/ 10.3168/jds.2011-4369.

Morgavi, D. P., E. Forano, C. Martin, and C. J. Newbold. 2010. Microbial ecosystem and methanogenesis in ruminants. Animal 4:10241036. https://doi.org/10.1017/S1751731110000546.

Negussie, E., Y. de Haas, F. Dehareng, R. J. Dewhurst, J. Dijkstra, N. Gengler, D. P. Morgavi, H. Soyeurt, S. van Gastelen, T. Yan, and F. Biscarini. 2017. Invited review: Large-scale indirect measurements for enteric methane emissions in dairy cattle: A review of proxies and their potential for use in management and breeding decisions. J. Dairy Sci. 100:2433-2453. https://doi.org/10.3168/ jds.2016-12030.
Newbold, C. J., and E. Ramos-Morales. 2020. Review: Ruminal microbiome and microbial metabolome: effects of diet and ruminant host. Animal 14:s78-s86. https://doi.org/10.1017/S1751731119003252.

OECD. 2019. Enhancing Climate Change Mitigation through Agriculture. OECD Publishing.

Pinotti, L., A. Baldi, and V. Dell'Orto. 2002. Comparative mammalian choline metabolism with emphasis on the high-yielding dairy cow. Nutr. Res. Rev. 15:315-332. https://doi.org/10.1079/NRR200247.

Pujos-Guillot, E., M. Brandolini, M. Petera, D. Grissa, C. Joly, B Lyan, E. Herquelot, S. Czernichow, M. Zins, M. Goldberg, and B. Comte. 2017. Systems metabolomics for prediction of metabolic syndrome. J. Proteome Res. 16:2262-2272. https://doi.org/ 10.1021/acs.jproteome.7b00116.

Rico, D. E., P. Y. Chouinard, F. Hassanat, C. Benchaar, and R. Gervais. 2016. Prediction of enteric methane emissions from Holstein dairy cows fed various forage sources. Animal 10:203-211. https:/ /doi.org/10.1017/S1751731115001949.

Saro, C., U. M. Hohenester, M. Bernard, M. Lagrée, C. Martin, M. Doreau, H. Boudra, M. Popova, and D. P. Morgavi. 2018. Effectiveness of interventions to modulate the rumen microbiota composition and function in pre-ruminant and ruminant lambs. Front. Microbiol. 9:1273. https://doi.org/10.3389/fmicb.2018.01273.

Shennan, D. B., and M. Peaker. 2000. Transport of milk constituents by the mammary gland. Physiol. Rev. 80:925-951. https://doi.org/ 10.1152/physrev.2000.80.3.925.

Shetty, N., G. Difford, J. Lassen, P. Lovendahl, and A. J. Buitenhuis. 2017. Predicting methane emissions of lactating Danish Holstein cows using Fourier transform mid-infrared spectroscopy of milk. J. Dairy Sci. 100:9052-9060. https://doi.org/10.3168/jds.2017-13014.

Smith, C. A., E. J. Want, G. O'Maille, R. Abagyan, and G. Siuzdak. 2006. XCMS: Processing mass spectrometry data for metabolite profiling using nonlinear peak alignment, matching, and identification. Anal. Chem. 78:779-787. https://doi.org/10.1021/ac051437y.

Sundekilde, U. K., P. D. Frederiksen, M. R. Clausen, L. B. Larsen, and H. C. Bertram. 2011. Relationship between the metabolite profile and technological properties of bovine milk from two dairy breeds elucidated by NMR-based metabolomics. J. Agric. Food Chem. 59:7360-7367. https://doi.org/10.1021/jf202057x.

Sundekilde, U. K., L. B. Larsen, and H. C. Bertram. 2013. NMRbased milk metabolomics. Metabolites 3:204-222. https://doi.org/ $10.3390 /$ metabo3020204.

Thauer, R. K. 2019. Methyl (alkyl)-coenzyme M reductases: Nickel F430-containing enzymes involved in anaerobic methane formation and in anaerobic oxidation of methane or of short chain alkanes. Biochemistry 58:5198-5220. https://doi.org/10.1021/acs.biochem .9b00164.

Thiel, A., R. Rumbeli, P. Mair, H. Yeman, and P. Beilstein. 2019a. 3-NOP: ADME studies in rats and ruminating animals. Food Chem. Toxicol. 125:528-539. https://doi.org/10.1016/j.fct.2019.02 .002 .

Thiel, A., A. C. M. Schoenmakers, I. A. J. Verbaan, E. Chenal, S. Etheve, and P. Beilstein. 2019b. 3-NOP: Mutagenicity and genotoxicity assessment. Food Chem. Toxicol. 123:566-573. https://doi .org/10.1016/j.fct.2018.11.010.

Ulrich, E. L., H. Akutsu, J. F. Doreleijers, Y. Harano, Y. E. Ioannidis, J. Lin, M. Livny, S. Mading, D. Maziuk, Z. Miller, E. Nakatani, C. F. Schulte, D. E. Tolmie, R. Kent Wenger, H. Yao, and J. L. Markley. 2008. BioMagResBank. Nucleic Acids Res. 36(Database):D402-D408. https://doi.org/10.1093/nar/gkm957.

van der Kloet, F. M., I. Bobeldijk, E. R. Verheij, and R. H. Jellema. 2009. Analytical error reduction using single point calibration for accurate and precise metabolomic phenotyping. J. Proteome Res. 8:5132-5141. https://doi.org/10.1021/pr900499r.

van Gastelen, S., E. C. Antunes-Fernandes, K. A. Hettinga, and J. Dijkstra. 2017. Relationships between methane emission of Holstein Friesian dairy cows and fatty acids, volatile metabolites and non-volatile metabolites in milk. Animal 11:1539-1548. https:// doi.org/10.1017/S1751731117000295.

van Gastelen, S., E. C. Antunes-Fernandes, K. A. Hettinga, and J. Dijkstra. 2018a. The relationship between milk metabolome and 
methane emission of Holstein Friesian dairy cows: Metabolic interpretation and prediction potential. J. Dairy Sci. 101:2110-2126. https://doi.org/10.3168/jds.2017-13334.

van Gastelen, S., and J. Dijkstra. 2016. Prediction of methane emission from lactating dairy cows using milk fatty acids and midinfrared spectroscopy. J. Sci. Food Agric. 96:3963-3968. https:// doi.org/10.1002/jsfa.7718

van Gastelen, S., J. Dijkstra, G. Binnendijk, S. M. Duval, J. M. L. Heck, M. Kindermann, T. Zandstra, and A. Bannink. 2020. 3-Nitrooxypropanol decreases methane emissions and increases hydrogen emissions of early lactation dairy cows, with associated changes in nutrient digestibility and energy metabolism. J. Dairy Sci. 103:8047-8093. https://doi.org/10.3168/jds.2019-17936.

van Gastelen, S., H. Mollenhorst, E. C. Antunes-Fernandes, K. A. Hettinga, G. G. van Burgsteden, J. Dijkstra, and J. L. W. Rademaker. 2018b. Predicting enteric methane emission of dairy cows with milk Fourier-transform infrared spectra and gas chromatographybased milk fatty acid profiles. J. Dairy Sci. 101:5582-5598. https:/ /doi.org/10.3168/jds.2017-13052.

Vanlierde, A., M. L. Vanrobays, F. Dehareng, E. Froidmont, H. Soyeurt, S. McParland, E. Lewis, M. H. Deighton, F. Grandl, M. Kreuzer, B. Gredler, P. Dardenne, and N. Gengler. 2015. Hot topic: Innovative lactation-stage-dependent prediction of methane emissions from milk mid-infrared spectra. J. Dairy Sci. 98:57405747. https://doi.org/10.3168/jds.2014-8436.

Villeneuve, M. P., Y. Lebeuf, R. Gervais, G. F. Tremblay, J. C. Vuillemard, J. Fortin, and P. Y. Chouinard. 2013. Milk volatile organic compounds and fatty acid profile in cows fed timothy as hay, pasture, or silage. J. Dairy Sci. 96:7181-7194. https://doi.org/10 $.3168 /$ jds.2013-6785.

Vlaeminck, B., V. Fievez, A. Cabrita, A. Fonseca, and R. Dewhurst. 2006. Factors affecting odd-and branched-chain fatty acids in milk: A review. Anim. Feed Sci. Technol. 131:389-417. https://doi.org/ 10.1016/j.anifeedsci.2006.06.017.

Wallace, R. J., R. Onodera, and M. A. Cotta. 1997. Metabolism of nitrogen-containing compounds. Pages $283-328$ in The Rumen Microbial Ecosystem. Second ed. P. N. Hobson and C. S. Stewart, ed. Chapman and Hall.

Wallimann, T., M. Tokarska-Schlattner, and U. Schlattner. 2011. The creatine kinase system and pleiotropic effects of creatine. Amino Acids 40:1271-1296. https://doi.org/10.1007/s00726-011-0877-3.

Webster, T. M., A. L. Smith, R. R. Reddy, A. J. Pinto, K. F. Hayes, and L. Raskin. 2016. Anaerobic microbial community response to methanogenic inhibitors 2-bromoethanesulfonate and propynoic acid. MicrobiologyOpen 5:537-550. https://doi.org/10.1002/mbo3 .349 .
Wikoff, W. R., A. T. Anfora, J. Liu, P. G. Schultz, S. A. Lesley, E. C. Peters, and G. Siuzdak. 2009. Metabolomics analysis reveals large effects of gut microflora on mammalian blood metabolites. Proc. Natl. Acad. Sci. USA 106:3698-3703. https://doi.org/10.1073/ pnas.0812874106.

Yang, Y., N. Zheng, X. Zhao, Y. Zhang, R. Han, J. Yang, S. Zhao, S. Li, T. Guo, C. Zang, and J. Wang. 2016. Metabolomic biomarkers identify differences in milk produced by Holstein cows and other minor dairy animals. J. Proteomics 136:174-182. https://doi.org/ 10.1016/j.jprot.2015.12.031

Yanibada, B. H. Boudra, L. Debrauwer, C. Martin, D. P. Morgavi, and C. Canlet. 2018. Evaluation of sample preparation methods for NMR-based metabolomics of cow milk. Heliyon 4:e00856. https://doi.org/10.1016/j.heliyon.2018.e00856.

Yanibada, B., H. Boudra, and D. P. Morgavi. 2021. Supporting data for "Milk metabolome reveals variations on enteric methane emissions from dairy cows fed a specific inhibitor of the methanogenesis pathway.". Portail Data INRAE V1. https://doi.org/10.15454/ UUZIGD.

Yanibada, B., U. Hohenester, M. Pétéra, C. Canlet, S. Durand, F. Jourdan, J. Boccard, C. Martin, M. Eugène, D. P. Morgavi, and H. Boudra. 2020. Inhibition of enteric methanogenesis in dairy cows induces changes in plasma metabolome highlighting metabolic shifts and potential markers of emission. Sci. Rep. 10:15591. https://doi.org/10.1038/s41598-020-72145-w.

Zheng, X., G. Xie, A. Zhao, L. Zhao, C. Yao, N. H. L. Chiu, Z. Zhou, Y. Bao, W. Jia, J. K. Nicholson, and W. Jia. 2011. The footprints of gut microbial-mammalian co-metabolism. J. Proteome Res. 10:5512-5522. https://doi.org/10.1021/pr2007945.

Zhou, Z., Q. Meng, and Z. Yu. 2011. Effects of methanogenic inhibitors on methane production and abundances of methanogens and cellulolytic bacteria in in vitro ruminal cultures. Appl. Environ. Microbiol. 77:2634-2639. https://doi.org/10.1128/AEM.02779-10.

\section{ORCIDS}

Bénédict Yanibada 느 https://orcid.org/0000-0001-5007-0603

Mélanie Pétéra ๑ https://orcid.org/0000-0002-1779-6901

Fabien Jourdan @ https://orcid.org/0000-0001-9401-2894

Anne Ferlay 이 https://orcid.org/0000-0002-0651-792X

Diego P. Morgavi ๑ https://orcid.org/0000-0002-3883-0937 